\title{
Convergences of joint, positive interactions and regulation in collaborative learning
}

\begin{abstract}
This qualitative study explores the convergences of small groups' joint and positive interactions and regulation in social interaction during collaborative learning. We analyzed the video-recorded social interactions of five groups of student teachers during environmental science tasks. We examined the frequency and functions of the situations in which joint participation and positive socio-emotional interaction converged with regulation (planning, monitoring, and evaluating) in social interaction. The results show that when groups planned, monitored, or evaluated their learning, they participated more jointly in social interaction and showed more socio-emotional support than in interactions with no observed regulation. The situations in which these elements converged served three functions: establishing agreement, responding to challenges or mistakes, and discussing strengths and weaknesses. The results suggest that the convergences of joint and positive interactions and regulation in social interaction can serve a function that is meaningful for collaborative learning progress.
\end{abstract}

Keywords: social interaction, collaborative learning, regulation, socio-emotional interaction, joint participation 


\section{Convergences of joint, positive interactions and regulation in collaborative learning}

Collaborative learning in small groups is a process that involves "demanding, resource-consuming skills of coordination ... as well as affective, interpersonal ones" (Kuhn, 2015, pp. 51). These processes are mediated and shaped by social interaction (Kreijns, Kirschner, \& Jochems, 2003) over the course of groups' development (Fransen, Weinberger, \& Kirschner, 2013). Collaborative learning involves group members' mutually engaged and coordinated effort on a shared task (Roschelle \& Teasley, 1995), in contrast to cooperative learning, where group members split the work on a shared task and collect contributions together (Baker, 2015; Dillenbourg, 1999). Mutual engagement and coordinated effort cannot be taken for granted in collaborative learning (Kuhn, 2015; Miyake \& Kirschner, 2014); rather, it requires that groups participate in social interaction in a joint and socio-emotionally positive manner (Kreijns, Kirschner, \& Jochems, 2003; Linnenbrink-Garcia, Rogat, \& Koskey, 2011) and regulate their efforts toward learning (Janssen, Erkens, Kirschner, \& Kanselaar, 2010).

In this qualitative study, we explore the convergences of these two important components of collaborative learning: joint, positive interactions as well as regulation in social interaction. Research on social interaction in collaborative learning has highlighted that joint participation, i.e., participation by all group members, and a positive tone of interactions foster learners' ability to work together particularly during demanding tasks (e.g., Barron, 2003; Mullins, Deiglmayr, \& Spada, 2013; Roschelle \& Teasley, 1995). Studies on regulation in collaborative learning have shown that skillful collaborators can regulate their joint learning by interactively planning, monitoring, and evaluating their learning (e.g., Khosa \& Volet, 2014; Kwon, Hong, \& Laffey, 2013; Näykki, Järvenoja, Järvelä, \& Kirschner, 2017). We posit that joint and positive interaction and regulation in social interaction can set the stage for engaging in productive co-elaboration of knowledge (Baker, 2009), given that 
groups use these means to foster their ability to explore, debate, and integrate divergent perspectives (Weinberger \& Fischer, 2006).

Recent studies have tentatively suggested that groups efforts to regulate their learning in social interaction may correlate with how group members participate in social interaction and what is the emotional tone of their interactions (e.g., De Backer, Van Keer, \& Valcke, 2015; Kwon, Liu, \& Johnson, 2014; Rogat \& Linnenbrink-Garcia, 2011). However, most studies rely on summative information and have less frequently addressed the fact that participation and the emotional tone of social interaction fluctuate during the flow of collaborative learning (e.g., Määttä, Järvenoja, \& Järvelä, 2012; Pekrun \& LinnenbrinkGarcia, 2012) and planning, monitoring and evaluating of learning emerge only in moments when they are purposeful (Hadwin, Järvelä, \& Miller, 2017). It is less clear if these elements fluctuate independently of each other, or if they converge in social interaction in situations that influence the progress of collaborative learning. Some recent preliminary evidence points to this direction (Bakhtiar, Webster, \& Hadwin, 2018; Isohätälä, Järvenoja and Järvelä, 2017), but further evidence of the frequency and functions of the convergences of joint and positive interactions and regulation in social interaction is warranted.

\section{Regulation in Social Interaction}

Our perspective on regulation in social interaction stems from self-regulated learning theory; that is, regulation of learning is the strategic, cyclical planning, monitoring, control, and evaluation of the cognitive, behavioral, motivational, and emotional conditions of learning whenever needed (Pintrich, 2000; Winne \& Hadwin, 1998; Zimmerman, 2000). In collaborative learning, these strategic processes extend beyond the individual members of a group through the medium of social interaction (Hadwin et al., 2017; Hadwin \& Oshige, 2011). Though regulation of learning is a mental process that originates in learners' 
intentions, beliefs, and past socio-historical experiences (Hadwin et al., 2017), regulation in collaborative learning is also an inherently interactive process.

The visible signs of regulation are actions and interactions that show learners' planning, monitoring, and evaluating behavior of their own learning and the joint learning efforts of the group (Järvelä \& Hadwin, 2013). Regulation in collaborative learning encompasses the regulation of one's own learning (self-regulation), initiatives to regulate others' learning (co-regulation), and the collectively negotiated regulation of the group's joint learning (socially shared regulation; Hadwin et al., 2017). In collaborative learning, regulatory initiations and decisions need to be verbalized and discussed between learners (Hurme, Merenluoto, \& Järvelä, 2009; Iiskala, Vauras, Lehtinen, \& Salonen, 2011; Järvenoja \& Järvelä, 2013). Thus, in this study, we refer to students' verbalized and group-level planning, monitoring and evaluating of their learning efforts as regulation in social interaction. This can be observed in moments where, for example, students negotiate a learning goal, share perceptions of their ways of working, or assess their performance.

The way small groups enact regulation in social interaction is situated (Järvenoja, Järvelä, \& Malmberg, 2015) and dependent on the affordances and constraints of the given context, for example the task or group members' emotional state (Hadwin et al., 2017). Not all regulation is productive for learning (e.g., self-handicapping; Wolters, 2003), but the literature shows that regulation in social interaction is needed in collaborative learning. For example, regulation in social interaction can have a positive role in supporting group performance (Näykki, Järvenoja, et al., 2017; Volet, Vauras, \& Salonen, 2009), directing cognitive efforts (Iiskala, Volet, Lehtinen, \& Vauras, 2015; Molenaar \& Chiu, 2014; Volet, Summers, \& Thurman, 2009), and fostering a better socio-emotional climate (Bakhtiar et al., 2018; Järvenoja \& Järvelä, 2013; Näykki, Järvelä, Kirschner, \& Järvenoja, 2014). 


\section{Joint, Positive Interactions}

Studies on collaborative learning emphasize that the quality of groups' social interactions play a key role in collaborative learning. Collaboration entails that participants reciprocally influence each other and their interaction involves space for negotiation (Dillenbourg, 1999). Quality of interaction is relevant for shaping the socio-emotional processes (Kreijns et al., 2003), relational space (Barron, 2003; Janssen et al., 2010), or group processes (Rogat \& Linnenbrink-Garcia, 2011) of collaborative learning, which support groups' ability to constructively and cohesively engage in co-elaboration of knowledge (Baker, Andriessen, \& Järvelä, 2013). This is enabled by social-behavioral engagement, which ideally manifests as students' joint participation and their positive interactions, such as respect and support for each other (Linnenbrink-Garcia et al., 2011; Pekrun \& LinnenbrinkGarcia, 2012).

In this study, we explore joint participation and positive socio-emotional interaction as signs of joint and positive interaction. We argue that joint participation requires that all group members, rather than only some, keep attuned and contribute to discussions reciprocally in order to pool and expand the knowledge of multiple learners (Barron, 2000, 2003; Cohen, 1994; Dillenbourg, 1999; Roschelle \& Teasley, 1995). Joint participation involves joint task focus, contributing, and listening, as reciprocal communication requires participants to initiate turns and provide evidence of understanding, and continued attention (Clark \& Brennan, 1991; Sacks, Schegloff, \& Jefferson, 1974). Joint participation in social interaction enables group members to make full use of collaborating with others by collectively sharing and converging knowledge (Roschelle, 1992). In addition, the main characteristics of collaborative learning include that learners interact in a positive manner by nurturing a respectful socio-emotional climate (Baker et al., 2013; Barron, 2003; Linnenbrink-Garcia et al., 2011) in which sharing and negotiation of ideas are welcome. Such a positive climate can 
manifest in subtle ways, including hedging of claims (Damsa, Ludvigsen, \& Andriessen, 2013; Isohätälä et al., 2018; Lakoff, 1972), but also through more explicit positive socioemotional interaction, such as encouragement, apologizing, and friendly laughter (Bakhtiar et al., 2018). Positive socio-emotional interactions can be used to manage the negative emotions or interactions aroused by socio-cognitive conflicts as students discuss divergent views or challenges (Andriessen, Baker, \& van der Puil, 2011; Polo, Lund, Plantin, \& Niccolai, 2016; Järvenoja, \& Järvelä, 2013).

We acknowledge that signs of joint and positive interactions are intertwined; that is, positive socio-emotional interactions can support joint participation (e.g. Barron, 2000, 2003; Linnenbrink-Garcia et al., 2011). However, failing to attend to respectful interaction can lead to unproductive participation, such as social loafing (Karau \& Williams, 1993; Salomon \& Globerson, 1989; Linnenbrink-Garcia et al., 2011). In contrast, focusing too much on social activities, such as supporting others emotionally, may hamper learning if the group fails to engage with the task (Janssen et al., 2010), or if they favor quick consensus building at the expense of exploring, debating, and integrating perspectives (Weinberger \& Fischer, 2006).

\section{Regulation and Joint, Positive Interaction}

Empirical work exploring small groups' joint, positive interaction and regulation in social interaction in parallel is relatively new. Studies have shown preliminary findings of how regulation in social interaction may relate to joint participation and socio-emotional interaction, though these concepts have been operationalized in various ways.

One of the first studies to explore regulation and groups members' joint participation in social interaction was by Volet et al. (2009), who compared the quality of regulation during knowledge co-construction in three groups of veterinary science students. The authors found that the group with more active participation overall also showed more evidence of high-level regulation during knowledge co-construction. Similar results were reported by Grau and 
Whitebread (2012), who compared regulation in social interaction among two groups of primary school children. Their findings showed that shared regulation was more common in the group with more symmetrical participation. Rogat and Linnenbrink-Garcia (2011) also showed that a group of upper-elementary students with high-quality regulation exhibited more collaborative participation (i.e., sharing ideas and working as a group rather than individually). More recently, the quality of interaction and regulation in social interaction was explored by De Backer et al. (2015) among educational science students. The authors found a positive correlation between socially shared metacognitive regulation and more transactive participation; that is, interaction where speakers' turns reflected previous turns by other group members.

In addition to joint participation, positive socio-emotional interactions have been found to connect to regulation in social interaction. Kempler and Linnenbrink (2006) were among the first to show how help-seeking as a form of regulation was connected to positive socio-emotional interactions - namely, respect and encouragement of participation. The study showed that sixth grade students' positive socio-emotional interaction fostered help-seeking and responses to requests for help. Volet et al. (2009) suggested that higher education students' who shared positive emotions, such as humor, may have facilitated high-level, coregulated knowledge co-construction. These findings were elaborated by Rogat and Linnenbrink-Garcia (2011), who suggested that positive socio-emotional interaction, which they operationalized as joint listening and respect, inclusion, and group cohesion, promoted higher quality regulation among upper-elementary students. Kwon et al. (2014) supported this by showing that more successful groups of undergraduates engaged both in more positive socio-emotional interaction — namely, encouragement and sense of community—and more adaptive regulatory behaviors. 
Thus, regulation in social interaction may be linked to groups' participation and positive socio-emotional interaction. All these elements may also be intertwined as suggested by Sinha, Rogat, Adams-Wiggings, and Hmelo-Silver (2015), who holistically characterized productive collaborative engagement as comprising active, task-focused participation and positive socio-emotional interaction paired with regulatory strategies and learning efforts. Similarly, research on team development has suggested that effective groups are able to create mutual trust and align mental models through reciprocal interaction, monitoring and adapting (Fransen et al., 2013). However, previous studies have mostly relied on summative information about regulation and participation, or regulation and socio-emotional interactions. Studies have less frequently addressed the temporal dynamics of small groups' collaborative learning (Arrow, Poole, Henry, Wheelan, \& Moreland, 2004), even though studies show that regulation emerges in social interaction at various time points according to situation-specific needs (Lee, O’Donnell, \& Rogat, 2014; Molenaar \& Chiu, 2014); and that students can fluctuate between more or less active participation (Määttä et al., 2012) and occasionally show more or less overt expressions of emotion (Bakhtiar et al., 2018). Thus, it is relevant to examine how small groups' joint and positive interactions and regulation in social interaction emerge in relation to each other during the temporal flow of collaborative learning.

A few recent studies have made observations about the temporal emergence of joint and positive interaction and regulation in social interaction. Isohätälä et al. (2017) showed that socially shared regulation of learning in higher education students' social interaction cooccurred with students' activated participation (i.e., all group members contributed). Lajoie et al. (2015), in turn, showed that positive socio-emotional interaction, such as complimenting, expressing appreciation, and encouraging contributions, frequently occurred during moments when learners evaluated their work. Järvelä, Järvenoja, Malmberg, Isohätälä, and Sobocinski (2016) found that socio-emotional interaction (i.e., interaction about positive or negative 
emotions or motivation; increasing or decreasing group cohesion, inducing laughter) was often involved in the planning phase of group work when learners activated beliefs and processes in preparation for the learning. Recently, Bakhtiar et al. (2018) illustrated the interplay between regulatory processes and socio-emotional interactions, suggesting that a positive climate group frequently incorporated positive socio-emotional interactions, such as encouraging participation and motivation, in regulating their learning. These findings imply that joint and positive interaction and regulation in social interaction may converge in social interaction. However, the frequency and functions of such situations are insufficiently explored.

\section{Research Questions}

We explored the frequency and function of the situations in which small groups' joint and positive interactions and regulation in social interaction converged during collaborative learning. The qualitative analysis was guided by two questions:

RQ1: How frequently do joint participation and positive socio-emotional interactions converge with regulation in social interaction?

RQ2: What functions do the convergences of joint participation, positive socioemotional interaction, and regulation in social interaction serve in collaborative learning?

\section{Method}

\section{Setting, Procedure, and Dataset}

The data were collected during a six-week environmental science course in teacher education at a Finnish university. The following principles guided the research design.

Participants' experience and dispositions related to collaborative learning. We selected a class of 19 first-year students in a teacher education program (12 women, 7 men, $M_{\text {age }}=23$ years) as the participants of this study. Student teachers were a justified choice as 
they represent young adults accustomed to collaborative learning, which is emphasized as a pedagogical practice in the local teacher education curriculum and already in all education in Finland. The students had spent several months studying together in the same class and had already collaborated with all or some of the members of their small group before the data collection occurred. Familiarity among the participants and sharing previous collaboration experiences was considered important because it can potentially enhance more efficient, critical, and exploratory communication and less need for the group members to get to know each other and create mutual trust (Janssen, Erkens, Kirschner, \& Kanselaar, 2009). Groups with little history may be ineffective at the start of their collaboration because groups members lack information of one another and have not fully developed a sense of psychological safety and group potency (Fransen et al., 2013; Raes, Kyndt, Decuyper, Van den Bossche, \& Dochy, 2015).

Participants' dispositions toward collaboration were considered in order to limit major differences between groups in students' motivation to collaborate. The participants were divided into five mixed-gender groups of three to four students on the basis of a prequestionnaire assessing the students' dispositions toward collaboration (Wang, 2009). The Likert-scaled items included measures such as "I enjoy exchanging thoughts." Students were divided into three profiles: the most positive toward collaboration, the least positive toward collaboration, and those in between. Each group included students from all three profiles.

Tasks that foster collaboration and regulation in social interaction. The groups were assigned to work on tasks relating to five environmental science topics: species, ecosystems, maps, planetary phenomena, and climate. In each 90-minute session, the groups were asked to collaboratively discuss a specific topic and design tasks for teaching the topic in elementary school. The students could take advantage of given materials and tools, such as handouts, books, the elementary school curriculum, and laptops and tablets. The goal of the 
tasks was to enhance students' conceptual and pedagogical understanding of given concepts and phenomena. The open-ended tasks required students to activate prior knowledge, negotiate their understandings, evaluate the relevance of the environmental science topics for children, and jointly design methods for teaching the topics. The tasks were considered to foster regulation in social interaction as more ill-structured tasks may afford more planning, monitoring and evaluating of learning than structured tasks (Molenaar \& Chiu, 2014).

As an example, the following instructions were given in the session about ecosystems: Discuss and plan how to teach forest ecosystems to fourth graders. Save your plan to Google Drive. Complete the following steps: (a) Define the core content, complementary content, and specialized content concerning the topic; (b) read Bloom's revised taxonomy of cognitive domains and create educational objectives and tasks for activating both high-order and low-order cognitive processes; and (c) share your plan with the other students in the class. Evaluate the plan of another group and give feedback using the Comment tool in Google Drive. Read and discuss the feedback your group has received.

Groups' collaborative learning was supported by a macro-script that facilitated discussion about goals, progress, and challenges of the group and the task (Näykki, Isohätälä, Järvelä, Pöysä-Tarhonen, \& Häkkinen, 2017). The 2 to 5 minute scripted discussions took place at the beginning and end of each group work session, and once during the group work. However, the scripted discussions (on average 7.5 minutes per video) were excluded from the analysis since they did not focus on task performance as such and could possibly increase participation due to the guidance that prompted students to answer script questions.

Quality of research setting and data. The course was run in a classroom-like research space with 360-degree cameras. The facilities supported authenticity of the learning setting as the space was designed to function as a normal classroom and was located in the 
premises where students take their classes. The data collection occurred on an environmental science course, which was part of the compulsory teacher education studies, but students could choose if they wanted to take part in the research. Twenty-four sessions were captured on video and 20 videos (22 h 15 min) were selected after excluding videos in which less than three students per group were present. After also excluding scripted discussions, the duration of material used for the analysis was 19 hours and 45 minutes long $\left(M_{\text {duration }}=59 \mathrm{~min}, S D=8\right.$ min). The dataset was considered sufficient for providing rich material for analyzing social interaction in several small groups and several collaborative tasks but not too extensive, which would limit the resources to conduct the micro-level analysis of social interaction.

Information of groups' performance. Students individually self-evaluated their motivation to collaborate before $\left(M_{\text {all groups }}=4.72, S D=.22\right)$ and after each session $\left(M_{\text {all }}\right.$ groups $=4.68, S D=.46$ ), on a five-point scale. Students also evaluated their perceptions of group potency before $\left(M_{\text {all groups }}=4.61, S D=.30\right)$ and after sessions $\left(M_{\text {all groups }}=4.53, S D=\right.$ .34). After all sessions, students evaluated their overall perceptions of their collaboration in terms of cohesion $\left(M_{\text {all groups }}=5.72, S D=.42\right.$; Sargent $\&$ Sue-Chan, 2001), satisfaction $\left(M_{\text {all }}\right.$ groups $=5.52, S D=.54$; Chang $\&$ Bordia, 2001$)$ and psychological safety $\left(M_{\text {all groups }}=5.67, S D\right.$ $=.51$; Edmondson, 1999), on a six-point scale. The evaluations show that students were motivated to collaborate and considered their collaboration efficacious, cohesive, effective and safe, which may have been supported by group members' familiarity and previous collaborations with each other (Raes et al., 2015). Thus, students' perceptions of the socioemotional climate in groups were positive and there were no considerable differences between the situations or groups. A teacher also evaluated groups' content knowledge $\left(M_{\text {all groups }}=\right.$ $2.79, S D=.60)$ and pedagogical knowledge and collaboration $\left(M_{\text {all groups }}=2.98, S D=.71\right)$ on the basis of the groups' interaction during each session, on a 4-point scale. The teacher evaluations showed a decent—neither particularly high nor low—performance by all groups 
and no considerable differences between the situations. These indicators gave reason to examine the dataset as a whole rather than focus on differences between groups.

\section{Data Analysis}

Video coding. The analysis of video data was assisted by QSR International's NVivo 10. The videos were segmented into 30 -second episodes. This was to establish a manageable and consistent unit of analysis, creating a temporally unfolding overview of the dataset for observing overlaps between phenomena. While other studies used longer, 5-minute episodes as the unit of analysis (e.g., Sinha et al., 2015; Sullivan \& Wilson, 2015), we considered thirty seconds short enough for making moment-by-moment observations, but long enough to observe several conversational turns in one episode and, thus, observe how elements of social interaction converged in the same episodes. Each episode was viewed and coded if the interaction within the given episode met the criteria of the coding scheme (introduced in the following paragraphs). The codes were not mutually exclusive, meaning that the same segment could be coded under several categories. However, as all coding categories had distinct criteria, the coding of one category (e.g., monitoring) was not dependent upon another (e.g., active contributing). The reliability of the analysis was checked by calculating the Cohen's kappa value of interrater reliability after two independent coders analyzed $30 \%$ of the dataset. The kappa value was sufficient $(\kappa \geq .69)$ for all categories.

The coding categories of regulation in social interaction were based on the theory of regulation of learning (Pintrich, 2000; Winne \& Hadwin, 1998; Zimmerman, 2000) and empirical research on regulation in social interaction (e.g., Kwon et al., 2014; Näykki, Järvenoja, et al., 2017; Rogat \& Linnenbrink-Garcia, 2011). Three categories were coded: planning (i.e., discussing the understanding of task instructions, goal-setting, or discussing how to work), monitoring (i.e., discussing content understanding, progress, task value or interest, or task difficulty), and evaluating (i.e., discussing performance or ways of working 
retrospectively). Since our focus was not on examining the characteristics of regulation as such, we did not distinguish the target of regulation (e.g., cognition or motivation) or the type of regulation (self-, co-, or shared regulation of learning). We acknowledge that we only captured the processes that became visible in speech and activity. However, our focus was on groups' social interactions, namely the convergences of joint and positive interactions and regulation in social interaction, and not on mental processes.

A coding category for groups' joint and positive interaction was developed on the basis of studies suggesting that these elements may be positively related to the emergence of regulation in social interaction (e.g., De Backer et al., 2015; Isohätälä et al., 2017; Kwon et al., 2014). Joint participation was investigated with three sub-categories: joint task focus (i.e., each group member is engaged in on-task behaviors), joint contributing (i.e., each group member contributes verbally to the discussion with more substantial turns than simple backchanneling), and joint listening (i.e., each group member indicates attunement by nodding, back-channeling turns, eye contact, and attentive gaze). Positive socio-emotional interaction was analyzed with two categories: socio-emotional support (i.e., encouraging, praising, complimenting, apologizing, explicating group cohesion, expressing sympathy) and humor (i.e., good-natured joking, showing amusement, laughing). Since the performance indicators reported above suggest that groups' collaborations were positive with no considerable differences between groups or situations, we focused on positive socio-emotional interactions rather than signs of less productive interactions, such as social loafing or negative emotions (See Linnenbrink-Garcia et al., 2011).

Frequency of convergences. In the first stage of analysis we examined how frequently joint participation and positive socio-emotional interactions converged with regulation in social interaction. After coding, the codes were made visible and convergences between coded categories could be observed. We examined how often joint participation and 
positive socio-emotional interaction occurred in the 30-second episodes that involved and did not involve regulation in social interaction. The proportions of joint task focus, joint contributing, joint listening, humor, and socio-emotional support were calculated out of the total duration of episodes with and without regulation in social interaction in each of the 20 videos. We compared the proportions and used the Mann-Whitney $U$ test to seek out differences in the proportions of joint participation and positive socio-emotional interaction between episodes with and without regulation in social interaction.

Function of convergences. The second stage of data analysis focused on exploring what functions the convergences of joint, positive interaction and regulation in social interaction served in groups' collaborative learning. Since the frequencies of convergences showed that episodes with regulation in social interaction converged with more joint contributing, joint task focus, and socio-emotional support than episodes without regulation, we continued to qualitatively examine and describe in-depth the situations where these particular elements converged. All episodes with converging regulation, joint contributing, joint task focus, and socio-emotional support in social interaction were examined via interaction analysis (Jordan \& Henderson, 1995). To begin, the first author viewed the episodes and wrote detailed descriptions, which paraphrased the discussion and included observations of students' activity. Verbatim transcriptions were written if paraphrasing did not suffice. The descriptions were complemented with descriptions of the interactions and activities preceding and following the episode in focus. This was to provide details about the context of the episode and changes that occurred in the flow of students' collaboration.

The descriptions were read by another researcher, who could also return to the videos. The two researchers discussed the characteristics and functions of the episodes and the similarities and differences that could be seen. Similar episodes were grouped and re-grouped until the authors could name distinct categories describing the functions of the episodes in the 
groups' collaborative learning. Next, the two researchers independently reviewed all episodes and identified one category for each episode. Only a few discrepancies emerged and they were negotiated until the authors reached $100 \%$ agreement. The characteristics of each category were described and case examples selected. The case examples were accompanied by transcripts, translated from Finnish to English.

\section{Results}

\section{Frequency of Convergences}

There were altogether 11 hours and 18 minutes of episodes $\left(M_{\text {duration }}=34\right.$ min per session) involving regulation in social interaction (planning, monitoring, evaluating) in the dataset. These episodes accounted, on average, for $58 \%(S D=14 \%)$ of the group interaction during the 20 collaborative sessions. Differences were found in the frequency of joint participation and positive socio-emotional interaction between episodes with and without regulation in social interaction (Table 1). First, episodes with regulation in social interaction involved contributions by all group members more frequently than episodes without regulation. All the students' contributions were not necessarily considered to be regulation, but contributing was more prevalent in episodes where at least some turns involved planning, monitoring, or evaluating. The difference in the proportion of joint contributing was considerable between episodes with regulation $\left(M=46 \%, M_{\text {rank }} 25.92\right)$ and without regulation $\left(M=29 \%, M_{\text {rank }} 15.08\right.$; Mann-Whitney $\left.U=91.50, p=.003\right)$. In addition, all group members were more focused on the task during episodes with regulation in social interaction than without. The proportion of joint task focus was higher in episodes with regulation $(M=81 \%$, $\left.M_{\text {rank }} 25.12\right)$ than without regulation $\left(M=68 \%, M_{\text {rank }} 15.88\right.$; Mann-Whitney $U=107.50, p=$ .011). Joint listening was, on average, slightly more frequent during episodes with regulation $(M=58 \%)$ than without regulation $(M=53 \%)$, but there was variety in the proportions of joint listening; thus, no consistent differences were found. 
In terms of positive socio-emotional interaction, episodes with regulation in social interaction consistently involved a larger proportion of socio-emotional support than episodes without regulation. The difference in the proportion of socio-emotional support was considerable during episodes with regulation $\left(M=14 \%, M_{\text {rank }} 27.52\right)$ compared to episodes without regulation $\left(M=6 \%, M_{\text {rank }} 13.48\right.$; Mann-Whitney $\left.\mathrm{U}=59.50, p<.001\right)$. In contrast, regulation occurred sometimes with more and sometimes with less humor than episodes without regulation. Hence, no consistent differences were seen.

The results show that during episodes with regulation in social interaction, the groups were more often jointly focused on the task at hand and participated more actively in the discussion than during episodes without regulation. Thus, in episodes without regulation in social interaction, it was more common for members of the groups to not to contribute to the discussion or fall off task. Thus, in the fluctuation of groups' participation in social interaction, the more active moments of participation were often ones where students planned, monitored or evaluated their learning. Additionally, episodes with regulation in social interaction were more commonly met with interaction, where students encouraged or praised each other or explicitly stated positive team spirit. In interaction without explicit regulation, socio-emotional support was considerably rarer.

\section{Function of Convergences}

In the second stage of this study, we investigated what function the convergences of groups' joint and positive interactions and regulation in social interaction served during collaborative learning. We focused on the situations in which regulation in social interaction converged with joint task-focus, joint contributing and socio-emotional support - that is, the elements of joint and positive interactions that were more frequent during episodes with than without regulation. We identified 81 episodes (total duration $40 \mathrm{~min} 30 \mathrm{~s}$ ) where all given elements (regulation, joint contributing, joint task focus, socio-emotional support) converged. 
On average, there were 4 episodes $(S D=2.3)$ per session in the 20 sessions and no considerable differences between groups. Iterative qualitative analyses revealed that these situations served three functions in collaborative learning: Establishing agreement $(n=43)$, Responding to challenges or mistakes $(n=24)$, Discussing strengths or weaknesses $(n=14)$.

\section{Establishing Agreement}

The moments of establishing agreement were the most frequent situations $(n=43)$ where regulation, socio-emotional support, joint task focus, and joint contributing converged. In these moments, the groups discussed and approved ideas regarding their task or their ways of working. Regulation and socio-emotional support converged in social interaction in two ways. In the first case, the discussions began with an idea related to the task (e.g., "Pupils could compare two different types of forest") and socio-emotional support in the form of positive appraisal and agreement with the idea ("Yes, nice idea"). This was followed by planning what to do next ("Let's write it down") or monitoring where the group was in relation to its goals ("Then we're only missing the second part of the task").

In the second case, the discussions were initiated by planning what to do ("Should we use the categorization given in the curriculum?") or monitoring progress ("It seems we are nearly finished"). These statements were followed by approval and positive appraisal of the suggestion or statement (“Great job”). Occasionally, socio-emotional support emerged as ways of showing respect for others' wishes, for example, by suggesting a change of seats so that a peer could more easily participate. In such situations of agreeing on ways of working, socio-emotional support was incorporated in planning statements. Across situations, joint participation was helpful for the idea to be verbalized, approved and positively appraised before moving on. Positive appraisals created a climate of respect and approval of ideas.

Example 1 (Table 2) illustrates two occurrences (highlighted with gray color) of establishing agreement in group 4 (Aaron, Ellen, Maria) during session 3 about maps. The 
group is developing a task about maps for elementary school students. At 56:30-57:00 the group agrees on the fact that the pupils will draw a map using an aerial image. In the next episode of establishing agreement (58:00-58:30), the group agrees to elaborate the idea.

The discussion (56:30-57:00) is initiated by Maria, who prompts the group to make a decision regarding their ideas (1). Ellen monitors the group's progress by explicitly asking if the group has agreed that the pupils will draw their own map (2) as Maria proposed earlier. Perhaps because the idea of drawing was initially proposed by Maria, she does not impose her idea upon the group and simply states that the idea is an option (3). Ellen, in turn, shows socio-emotional support by praising the idea (4). She also signals acceptance and monitors her motivation by admitting that she would rather not weigh other options (7). Maria justifies the idea (8) and Aaron clarifies details (9), indicating that the idea can be pursued. Maria further expresses her support (10). Thus, explicit monitoring accompanied with positive appraisals and signs of acceptance helps the group establish agreement. Accordingly, the interaction continues with task performance in the following minute (57:00-58:00): Aaron and Maria discuss what kind of aerial image to use, while Ellen writes notes. At this time, no socioemotional support or regulation in social interaction occurs and the level of participation decreases as Ellen focuses on writing notes.

The following episode of establishing agreement (58:00-58:30) is initiated by Maria, who asks if drawing a map on the basis of an aerial picture is meaningful enough. She suggests that the pupils could also add elements to their map (11). The idea had been mentioned earlier by Ellen, who supports the suggestion (12). Maria, in turn, shows socioemotional support by praising Ellen's idea and enforcing the praise by gesturing toward her (15). She shows planning by suggesting that the group adopt the idea (17). Aaron elaborates the suggestion (19). Ellen, who is making notes, finishes the episode with a planning statement and asks the group if she should write the idea down. The others accept, and thus, in 
the following interaction (58:30-59:00), Maria continues to discuss further details of the task, Ellen makes notes, and Aaron quietly searches for information. Thus, based on discussing a new idea, positively appraising it, and explicitly deciding to move forward with the idea, the group revises their plan of action in agreement with each other. Consequently, participation decreases and neither regulation nor socio-emotional support emerges, as some group members concentrate on task activities in accordance with the revised plan.

\section{Responding to Challenges or Mistakes}

The moments when students responded to challenges or mistakes $(n=24)$ began with the realization of a fault or a challenge related to students' understanding, motivation, or emotion, technology, or group work. The challenge or mistake could be identified by explicit statements of emotion or faults, such as "I am tired" or "You were right, actually," or it was implicitly expressed (e.g., frowning, cursing, inability to move on). Regulation in social interaction was involved as monitoring or planning. Monitoring was often incorporated in the more explicitly stated challenges or mistakes, such as "I am frustrated that we don't have the books we need" or "I didn't realize you were not ready." Planning (“Let's try this!”), in turn, could occur before the realization of a challenge or mistake that was preventing the group from moving on to the next step. Sometimes planning occurred after the challenge and offered a way to move forward ("Should we take another piece of paper"). Socio-emotional support was an important part of these episodes. Challenges and mistakes triggered others to provide socio-emotional support by encouraging their peers, expressing sympathy, or apologizing. Occasionally, socio-emotional support served as a way of controlling the negative emotions caused by the challenge or mistake (see Example 2). Joint participation, in turn, allowed the whole group to become aware of the challenge or mistake and respond to it at the group level.

Example 2 (see Table 3) shows how group 3 (Sophia, Amanda, Victor) responded to a challenge in session 4 about planetary phenomena. The group is discussing how to teach the 
changing of seasons to children, when a challenge in content understanding emerges. The discussion spans across three consecutive 30-second episodes (44:00-45:30) that involve monitoring, joint focus, joint contributing, and socio-emotional support.

The discussion begins as Sophia looks at a map on which, a few moments earlier, Amanda marked the location of Finland. Sophia points to the map and asks if the location is, in fact, different (1). This statement questions Amanda's earlier idea. Amanda responds by explaining that she did not intend to show the exact location (2). Victor backs Amanda up (3). Sophia, perhaps acknowledging that her statement may have put Amanda's skills into question, shows socio-emotional support by apologizing and confirming that she has understood Amanda's intention (5). Sophia continues with a monitoring statement explaining that she had a moment of realization (5). However, as she starts to explain herself and overtly monitors her understanding, she notices that her realization was actually wrong (8) and jokingly states that she will keep quiet now (10).

The group continues to explore the map as Amanda and Victor explain to Sophia what they see (11-16). Sophia restates her mistake and shows socio-emotional support by acknowledging that Amanda was right and monitoring her understanding by stating that she did not have a moment of realization (17). Amanda points out that the group should pay attention to the angle of Earth (18-22). Sophia monitors her understanding by noting that she was thinking about the angle of Earth, but admits that she does not want to show her "stupidity" with the others, as they might laugh at her (23). Perhaps triggered by Sophia's fear of others laughing at her, Amanda reacts by giving socio-emotional support: she becomes more serious, makes eye contact with Sophia, and assures her that they will not laugh at her (24). The statement also signals explicit planning of the norms of interaction in the group. All three group members continue to lighten the mood by joking (25-30). In sum, the example shows how monitoring and joint participation allow the group to jointly assess if they made a 
mistake. The example shows how the mistake sparked signs of negative emotions in the way one of the students evaluated herself, but socio-emotional support helps control that the mistake does not become too socio-emotionally threatening for the group. After the challenge (45:30-46:30), students' joint task focus slightly diverges as the students count how long it has been since they studied planetary phenomena and move on to saving their work.

\section{Discussing Strengths and Weaknesses}

Moments of discussing strengths and weaknesses $(n=14)$ focused on the abilities or performance of the group or individual students. The moments arose when students were preparing for their tasks, discussing concepts, or reflecting on their performance. In terms of regulation in social interaction, these situations involved monitoring statements about content understanding ("We have an expert here"), progress ("We are all so sharp today"), or performance ("We worked rather well today"), which were elaborated by other students. In these cases, socio-emotional support was actually built into some or all of the monitoring or evaluating statements in the form of positive appraisals of the groups' understanding, progress, or performance. Joint participation by all group members enforced the formation of shared perceptions of the strengths — occasionally also the weaknesses — of the group.

Example 3 (Table 4) presents two consecutive episodes of discussing strengths and weaknesses of group 2 (Helen, Sara, May, Elias) in session 1 about species. Here, the group discusses the goals of teaching, but the discussion turns to the important role of Sara.

At the beginning, the group is exchanging ideas about the goals of teaching species. Helen suggests that pupils should be able to tie the species to different traits and compare species (1). As others agree $(2,4)$, Sara reformulates the idea to be written down (6). As Sara starts making notes, Helen shows socio-emotional support by praising how well Sara has reformulated the idea (9). May further incorporates socio-emotional support in monitoring by praising Sara's role in the group's progress (11). May enforces her support by patting Sara on 
the shoulder. The group shows amusement by laughing and smiling (10-15). Elias monitors the group's abilities by jokingly belittling the others' skills in contrast to Sara (14), which signals socio-emotional support for Sara, while the humorous tone signals that others should not be offended. Helen repeats her praise for Sara (17). Mixed up by the appraisals and laughter, Sara asks for help with remembering how she reformulated the idea $(17,19,21)$. The group is amused and jokingly monitors the fact that the well-formulated idea was forgotten (18-24). Helen is ultimately able to help Sara remember her formulation (26) and Sara can continue taking notes (27). In this episode, socio-emotional support is integrally incorporated in monitoring the group's — namely Sara's — strengths, while joint participation ensures that the positive appraisals are shared between the group members. After the spiritboosting episode, the discussion decelerates as Sara makes notes and the others turn their attention back to the books for information about species. No regulation or socio-emotional support emerges during the subsequent moments as the group focuses on task activities.

\section{Summary of Results}

The described situations illustrate how regulation, joint task focus, joint contributing, and socio-emotional support converged in situations that served the functions of establishing agreement, responding to challenges or mistakes, and discussing strengths and weaknesses. For example, in establishing agreement, socio-emotional support directed toward another group member's idea could indicate positive acceptance and induce the monitoring or planning of the group's progress. In responding to challenges, the monitoring of a problem in making progress could, in turn, trigger students to encourage each other or express sympathy. Socio-emotional support and monitoring could even converge in single statements, for example when students shared positive evaluations of their progress. The role of joint participation was to facilitate awareness and decision-making of ideas, challenges or perceptions through transactive turn-taking. As shown by the case examples, participation 
could decelerate after these moments as the group members turned their attention toward efforts in carrying out the task, such as taking notes. From this point of view, the situations served as points of coordination after which concentration-demanding activity could ensue.

\section{Discussion}

This study explored the frequency and function of the situations in which small groups' joint and positive interactions and regulation in social interaction converged during collaborative learning. The results show that during episodes with regulation in social interaction, the groups were more jointly focused on the task and all group members contributed more actively in the discussion than during interaction that did not involve regulation. This entails that in moments with no regulation in social interaction, it was more common for group members to fall off task or not to contribute actively. This result elaborates previous studies, which showed that more frequent regulation in social interaction is connected to higher overall rates of symmetrical, collaborative, attentive, and transactive social interaction (De Backer et al., 2015; Grau \& Whitebread, 2012; Rogat \& LinnenbrinkGarcia, 2011).

However, these previous studies did not examine when regulation emerges during the flow of social interaction and how it relates to fluctuations that can occur in learners' participation. The present study showed that it was the very moments with regulation in social interaction that involved increased task-focus and contributions by all group members. This result is in line with evidence suggesting that moments of regulation in social interaction coincide with more active participation and more peaks in students' participation compared to other task-focused interaction (Isohätälä et al., 2017). Only the degree of joint listening did not differ significantly between episodes with and without regulation in social interaction. Attunement is important for joint attentional engagement in face-to-face interaction (Barron, 2000), but it seems that moments of regulation in social interaction did not clearly relate to an 
increased need to signal listening, even though contributing and task focus were more prevalent.

In addition to participation, we found convergences between regulation and socioemotional support in social interaction. Compared to moments with no planning, monitoring or evaluating, episodes with regulation involved more interaction during which students encouraged or praised each other or stated positive team spirit. This result supports studies suggesting that students' positive socio-emotional interactions may be related to the overall frequency and quality of regulation in social interaction (e.g., Kwon et al., 2014; Rogat \& Linnenbrink-Garcia, 2011; Volet, Summers, et al., 2009). However, these studies have not examined in which situations regulation and positive socio-emotional interactions emerge and how they converge. The results of the current study suggest that socio-emotional support was more often incorporated into the very moments with regulation in social interaction than without. The result is in line with recent studies that have explored how aspects of regulation in social interaction, such as monitoring challenges, may intertwine socio-emotional interaction, such as encouragement (Lajoie et al., 2015; Järvelä, Järvenoja et al., 2016; Bakhtiar et al., 2018). However, though previous studies have noted humor as a part of positive socio-emotional interaction during moments with regulation in social interaction (e.g., Isohätälä et al., 2017; Volet, Summers, et al., 2009), the current study did not indicate an increased frequency of humor in episodes with regulation in social interaction. Thus, while humor may play a role in the socio-emotional climate of group work (Sullivan \& Wilson, 2015), it may not be induced or followed particularly by regulation in social interaction.

As tentatively suggested by prior research, the results of this study show that joint and positive interactions - namely, socio-emotional support and task-focused contributions by the whole group — indeed converged with regulation in social interaction. In the second part of our analysis, we identified that the situations in which these elements converged served three 
types of functions in collaborative learning: establishing agreement, responding to challenges or mistakes, and discussing strengths and weaknesses. Previous studies indicate that such situations serve as critical moments for the progress of collaborative learning. Agreeing and accepting constitute a crucial part of reaching and communicating joint understandings and decisions (e.g., Barron, 2000; Hmelo-Silver, 2003; Mäkitalo-Siegl, 2008) and forming shared mental models (Fransen et al., 2013). Creating awareness of challenges as well as strengths and weaknesses, in turn, can allow groups to overcome or avoid obstacles by planning and controlling their work to perform optimally (Järvenoja, Volet, \& Järvelä, 2013; Miller \& Hadwin, 2015; Näykki, Isohätälä et al., 2018). Thus, the results imply that joint, positive interactions and regulation in social interaction can converge in situations that are meaningful the progress of collaborative learning.

There are several potential reasons behind the convergences of regulation, joint participation, and socio-emotional interaction. In terms of regulation, joint task focus, and joint contributing, convergence is likely to stem from the fact that students' reciprocal turntaking helps them voice out their individual, potentially divergent understandings and form joint understandings (Clark \& Brennan, 1991) regarding the group's performance and progress. We suspect that in moments with no verbalized regulation in social interaction, learners occasionally participate less intensively in social interaction because they need mental capacity for cognitive processes, such as creating and evaluating ideas (Kirschner, Paas, \& Kirschner, 2009) and performing task-related actions, such as taking notes. Moments with regulation in social interaction, in turn, allow learners to re-group, monitor their progress, plan their actions, and resolve challenges, which is necessary for coordinated collaboration (Janssen et al., 2010). As pointed out by Barron $(2000,2003)$ and Roschelle and Teasley (1995), mutual engagement in collaborative learning need not be stable throughout the collaboration; rather, divergences in joint participation are normal as long as engagement 
regularly converges. In situations where a need for planning, monitoring and evaluating emerges, joint participation allows groups to verbalize that need and to collectively react to it (Iiskala et al., 2011, 2015; Järvenoja \& Järvelä, 2013; Järvenoja et al., 2015). Afterwards, groups can ensue activities needing more mental capacity. Our case examples show that participation could decrease after the moments of planning, monitoring or evaluating, because the students turned their focus back to other cognitive efforts, such as reading, or taking notes.

A possible explanation for the convergence of regulation and socio-emotional support in social interaction may stem from the fact that regulation activates learners' metacognitive thinking and discussion about the collaboration itself, such as goals, progress, and success (Hadwin et al., 2017). In moments of task performance with no regulation in social interaction, learners are mostly focused on content learning and cognitive activities, such as developing ideas. As groups begin to explicitly plan, monitor or evaluate their goals, progress, and success, the situation can give rise to emotional appraisals and responses. In other words, discussions involving regulation turn learners' attention from solely the cognitive processes and problem space of learning to the socio-emotional processes (Kreijns et al., 2003) or the relational space of collaboration as well (Barron, 2003; Janssen et al., 2010). In socioemotionally positive collaboration, it is likely that the responses students share about their collaborative learning are positive and serve to enhance socio-emotionally sound collaboration (Bakhtiar et al., 2018; Barron, 2003; Linnenbrink-Garcia et al., 2011).

It may also be that a challenge in understanding or discussing divergent points of view--which foster opportunities to learn--may create socio-emotional tension that needs to be managed by showing socio-emotional support (Andriessen, Pardijs, \& Baker, 2013; Polo et al., 2016). As a result, the students can enhance mutual trust and socio-emotional balance, even in the face of challenges (Barron, 2003; Järvenoja \& Järvelä, 2013; Näykki et al., 2014). From this perspective, socio-emotional support may be an integral part of the moments when 
students regulate their learning in social interaction. Our case examples illustrate how positive appraisals or encouragements were either triggered within the situations (e.g., by challenges) or built into the regulation in interaction (e.g., monitoring strengths).

The results emphasize that small groups' joint and positive interactions and regulation in social interaction during collaborative learning do not only occur as independent elements of social interaction. Our findings indicate that the convergences of these elements can serve a meaningful function in the progress of collaborative learning, enabling groups to establish agreement, respond to challenges or mistakes, and discuss strengths and weaknesses. Though individuals may be more or less active in contributing (Remedios, Clarke, \& Hawthorne, 2008; Hämäläinen \& Arvaja, 2009) and have different roles in regulating learning (Iiskala et al., 2015), convergences of regulation and joint, positive interaction can help groups to jointly coordinate their learning as a collective, while also attending to the interpersonal, affective processes of collaborative learning (Kuhn, 2015). These points of coordination, in turn, can allow students to return to more cognitive-oriented activities where mental capacity is needed for creating and negotiating ideas or performing task-related actions. Thus, these moments may help groups promote the balance between the costs of collaboration - namely, having to interact and function as a coordinated and cohesive group — and the benefits of collaboration — namely, being able to pool and expand knowledge of the participants (Janssen et al., 2010; Kirschner et al., 2009). Ideally, convergences of joint, positive interactions and regulation in social interaction support a sound socio-emotional climate and coordinated collaboration, setting the stage for productive co-elaboration of knowledge (Baker, 2009). However, these moments could also be counterproductive for learning if they simply lead the group to quick consensus-building (Weinberger, \& Fischer, 2006) or to focus on social, rather than cognitive activities (Janssen et al., 2010).

\section{Limitations}


This qualitative study was limited in the number of groups observed and the contextual constraints of the data collection. As the study was based on the analysis of social interaction in five groups of students in five collaborative sessions, the results are not generalizable, but they do represent a rich, descriptive process-oriented analysis of collaborative learning in an authentic learning setting. The results must be viewed in light of the context where the study was conducted, for example noting that the students were young adults who knew each other previously, which may have facilitated their ability to collaborate jointly and positively (Fransen et al., 2013). Further studies could examine how the convergences of joint and positive interaction and regulation in social interaction unfold in different stages of groups' development (Fransen et al., 2013), as the sense of psychological safety and group potency can grow (Raes et al., 2015). Future studies can also reveal if these convergences serve different functions in different contexts and how they influence how groups explore, debate and integrate divergent perspectives in order to learn.

In this study we focused on convergences, but did not analyze in detail how regulation and joint and positive interactions preceded or followed each other, which could shed more light on the temporal patterns of these processes. Furthermore, the results were dependent on the ways that we operationalized regulation in social interaction (planning, monitoring, evaluating) and groups' joint and positive interactions (joint participation, positive socioemotional interaction). Our operationalization was grounded on theory, but when comparing results, it is important to note that other studies may have used somewhat divergent concepts (e.g., other-regulation as a sign of regulation, sense of community as a sign of positive interaction). The field would benefit from efforts to make concepts uniform.

\section{Conclusions}

The qualitative approach of this study highlights the meaningful convergences of regulation and joint, positive interactions during small groups' collaborative learning. Based 
on the results, it may be important that teachers not only consider regulation and joint, positive interactions as separate elements of social interaction but acknowledge that they can be meaningfully converging ones. For example, pedagogical tools or scripts can be designed so that they do not only scaffold groups' planning or monitoring but also joint participation as well as positive appraisals and encouragements in instances of planning or monitoring. The results offer avenues for further exploring how such moments emerge in different learning contexts and, particularly, how the frequency or quality of convergences may influence the success of collaborative learning. Future process-oriented studies can also develop tools (see Azevedo, 2014; Järvelä, Kirschner, et al., 2016) that can track collaborative learning as an ongoing process. The results of the current study suggest that tracking the fluctuations in the level of participation or emotional tone of interaction could potentially help in developing the recognition of moments involving regulation in social interaction. A continued lack of joint participation could also signal the need to prompt groups to engage in coordinating their collaboration and possibly supporting each other socio-emotionally. 


\section{Funding}

This study was supported by the Academy of Finland (273970, 316129). 


\section{References}

Andriessen, J., Baker, M. J., \& van der Puil, C. (2011). Socio-cognitive tension in collaborative working relations. In S. Ludvigsen, A. Lund, I. Rasmussen, \& R. Säljö (Eds.), Learning across sites: New tools, infrastructures and practices (pp. 222-242). Abingdon, UK: Routledge.

Andriessen, J., Pardijs, M., \& Baker, M. J. (2013). Getting on and getting along: Tension in the development of collaboration. In M. J. Baker, J. Andriessen, \& S. Järvelä (Eds.), Affective learning together: Social and emotional dimensions of collaborative learning (pp. 205-230). New York, NY: Routledge.

Arrow, H., Poole, M. S., Henry, K. B., Wheelan, S., \& Moreland, R. (2004). Time, change, and development: The temporal perspective on groups. Small Group Research, 35, 73 105. doi:10.1177/1046496403259757

Azevedo, R. (2014). Issues in dealing with sequential and temporal characteristics of self- and socially-regulated learning. Metacognition and Learning, 9, 217-228. doi: $10.1007 / \mathrm{s} 11409-014-9123-1$

Baker, M. J. (2015). Collaboration in collaborative learning. Interaction Studies, 16, 451-473. doi:10.1075/is.16.3.05bak

Baker, M. J. (2009). Argumentative interactions and the social construction of knowledge. In N. M. Mirza \& A.-N. Perret-Clermont (Eds.), Argumentation and education: Theoretical foundations and practices (pp. 1-16). New York, NY: Springer.

Baker, M. J., Andriessen, J., \& Järvelä, S. (2013). Introduction: Visions of learning together. In M. J. Baker, J. Andriessen, \& S. Järvelä (Eds.), Affective learning together: Social and emotional dimensions of collaborative learning (pp. 1-30). Abingdon, UK: Routledge. 
Bakhtiar, A., Webster, E. A., \& Hadwin, A. F. (2018). Regulation and socio-emotional interactions in a positive and a negative group climate. Metacognition and Learning, 13, 57-90. doi:10.1007/s11409-017-9178-x

Barron, B. (2000). Achieving coordination in collaborative problem-solving groups. Journal of the Learning Sciences, 9(4), 403-436. doi:10.1207/S15327809JLS0904

Barron, B. (2003). When smart groups fail. Journal of the Learning Sciences, 12, 307-359. doi:10.1207/S15327809JLS1203

Chang, A., \& Bordia, P. (2001). A multidimensional approach to the group cohesion-group performance relationship. Small Group Research, 32, 379-405. doi:10.1177/104649640103200401.

Clark, H. H., \& Brennan, S. E. (1991). Grounding in communication. In L. B. Resnick, J. M. Levine, \& S. D. Teasley (Eds.), Perspectives on socially shared cognition (pp. 127-149). Washington, DC: American Psychological Association.

Cohen, E. G. (1994). Restructuring the classroom: Conditions for productive small groups. Review of Educational Research, 64, 1-35. doi:10.3102/00346543064001001

Damsa, D., Ludvigsen, S., \& Andriessen, J. (2013). Knowledge co-construction - epistemic consensus or relational assent? In M. J. Baker, J. Andriessen, \& S. Järvelä (Eds.), Affective Learning Together: Social and emotional dimensions of collaborative learning (pp. 97-119). Abingdon, UK: Routledge.

De Backer, L., Van Keer, H., \& Valcke, M. (2015). Exploring evolutions in reciprocal peer tutoring groups' socially shared metacognitive regulation and identifying its metacognitive correlates. Learning and Instruction, 38, 63-78.

doi:10.1016/j.learninstruc.2015.04.001 
Dillenbourg, P. (1999). What do you mean by “collaborative learning”? In P. Dillenbourg (Ed.), Collaborative learning: Cognitive and computational approaches (pp. 1-15). Oxford, England: Elsevier.

Edmondson, A. (1999). Psychological safety and learning behavior in work teams. Administrative Science Quarterly, 44, 350-352. doi:10.2307/2666999.

Fransen, J., Weinberger, A., \& Kirschner, P. A. (2013). Team effectiveness and team development in CSCL. Educational Psychologist, 48, 9-24. doi:10.1080/00461520.2012.747947

Grau, V., \& Whitebread, D. (2012). Self and social regulation of learning during collaborative activities in the classroom: The interplay of individual and group cognition. Learning and Instruction, 22, 401-412. doi:10.1016/j.learninstruc.2012.03.003

Hadwin, A. F., Järvelä, S., \& Miller, M. (2017). Self-regulation, co-regulation and shared regulation in collaborative learning environments. In D. Schunk \& J. Greene (Eds.), Handbook of self-regulation of learning and performance (2nd ed.). New York, NY: Routledge.

Hadwin, A. F., \& Oshige, M. (2011). Socially shared regulation: Exploring perspectives of social in self-regulated learning theory. Teachers College Record, 113, 240-264. doi:10.4324/9780203839010.ch5

Hmelo-Silver, C. E. (2003). Analyzing collaborative knowledge construction. Computers \& Education, 41, 397-420. doi:10.1016/j.compedu.2003.07.001

Hurme, T.-R., Merenluoto, K., \& Järvelä, S. (2009). Socially shared metacognition of preservice primary teachers in a computer-supported mathematics course and their feelings of task difficulty: A case study. Educational Research and Evaluation, 15, 503-524. doi:10.1080/13803610903444659 
Hämäläinen, R., \& Arvaja, M. (2009). Scripted collaboration and group-based variations in a higher education CSCL context. Scandinavian Journal of Educational Research, 53, 116. doi:10.1080/00313830802628281

Iiskala, T., Vauras, M., Lehtinen, E., \& Salonen, P. (2011). Socially shared metacognition of dyads of pupils in collaborative mathematical problem-solving processes. Learning and Instruction, 21, 379-393. doi:10.1016/j.learninstruc.2010.05.002

Iiskala, T., Volet, S. E., Lehtinen, E., \& Vauras, M. (2015). Socially shared metacognitive regulation in asynchronous CSCL in science: Functions, evolution and participation. Frontline Learning Research, 3(1), 78-111. doi:10.14786/flr.v3i1.159

Isohätälä, J., Järvenoja, H., \& Järvelä, S. (2017). Socially shared regulation of learning and participation in social interaction in collaborative learning. International Journal of Educational Research, 81, 11-24. doi:10.1016/j.ijer.2016.10.006

Isohätälä, J., Näykki, P., Järvelä, S., \& Baker, M. J. (2018). Striking a balance: Socioemotional processes during argumentation in collaborative learning interaction. Learning, Culture and Social Interaction, 16, 1-19. doi:10.1016/j.lcsi.2017.09.003

Janssen, J., Erkens, G., Kirschner, P. A., \& Kanselaar, G. (2009). Influence of group member familiarity on online collaborative learning. Computers in Human Behavior, 25, 161170. doi:10.1016/j.chb.2008.08.010

Janssen, J., Erkens, G., Kirschner, P. A., \& Kanselaar, G. (2010). Task-related and social regulation during online collaborative learning. Metacognition and Learning, 7, 25-43. doi:10.1007/s11409-010-9061-5

Jordan, B., \& Henderson, A. (1995). Interaction analysis: Foundations and practice. Journal of the Learning Sciences, 4, 39-103. doi:10.1207/s15327809j1s0401

Järvelä, S., \& Hadwin, A. F. (2013). New frontiers: Regulating learning in CSCL. Educational Psychologist, 48, 25-39. doi:10.1080/00461520.2012.748006 
Järvelä, S., Järvenoja, H., Malmberg, J., Isohätälä, J., \& Sobocinski, M. (2016). How do types of interaction and phases of self-regulated learning set a stage for collaborative engagement? Learning and Instruction, 43, 39-51.

doi:10.1016/j.learninstruc.2016.01.005

Järvelä, S., Kirschner, P. A., Hadwin, A. F., Järvenoja, H., Malmberg, J., Miller, M., \& Laru, J. (2016). Socially shared regulation of learning in CSCL: Understanding and prompting individual- and group-level shared regulatory activities. International Journal of Computer-Supported Collaborative Learning, 11, 263-280. doi:10.1007/s11412-016$9238-2$

Järvenoja, H., \& Järvelä, S. (2013). Regulating emotions together for motivated collaboration. In M. J. Baker, J. Andriessen, \& S. Järvelä (Eds.), Affective Learning Together: Social and emotional dimensions of collaborative learning (pp. 162-181). London, UK: Routledge.

Järvenoja, H., Järvelä, S., \& Malmberg, J. (2015). Understanding regulated learning in situative and contextual frameworks. Educational Psychologist, 50, 204-219. doi :10.1080/00461520.2015.1075400

Järvenoja, H., Volet, S. E., \& Järvelä, S. (2013). Regulation of emotions in socially challenging learning situations: An instrument to measure the adaptive and social nature of the regulation process. Educational Psychology, 33, 31-58.

doi:10.1080/01443410.2012.742334

Karau, S., \& Williams, K. (1993). Social loafing: A meta-analytic review and theoretical integration. Journal of Personality and Social Psychology, 65, 681-706. doi:10.1037/0022-3514.65.4.681

Kempler, T. M., \& Linnenbrink, E. A. (2006). Helping behaviors in collaborative groups in math: A descriptive analysis. In S. A. Karabenick \& R. S. Newman (Eds.), Help seeking 
in academic settings: goals, groups, and contexts (pp. 89-116). Mahwah, NJ: Lawrence Erlbaum.

Khosa, D. K., \& Volet, S. E. (2014). Productive group engagement in cognitive activity and metacognitive regulation during collaborative learning: Can it explain differences in students' conceptual understanding? Metacognition and Learning, 9, 287-307. doi:10.1007/s11409-014-9117-z

Kirschner, F., Paas, F., \& Kirschner, P. A. (2009). A cognitive load approach to collaborative learning: United brains for complex tasks. Educational Psychology Review, 21, 31-42. doi:10.1007/s10648-008-9095-2

Kreijns, K., Kirschner, P. A., \& Jochems, W. (2003). Identifying the pitfalls for social interaction in computer-supported collaborative learning environments: A review of the research. Computers in Human Behavior, 19, 335-353. doi:10.1016/S0747$5632(02) 00057-2$

Kuhn, D. (2015). Thinking together and alone. Educational Researcher, 44, 46-53. doi:10.3102/0013189X15569530

Kwon, K., Hong, R. Y., \& Laffey, J. M. (2013). The educational impact of metacognitive group coordination in computer-supported collaborative learning. Computers in Human Behavior, 29, 1271-1281. doi:10.1016/j.chb.2013.01.003

Kwon, K., Liu, Y.-H., \& Johnson, L. P. (2014). Group regulation and social-emotional interactions observed in computer supported collaborative learning: Comparison between good vs. poor collaborators. Computers \& Education, 78, 185-200. doi:10.1016/j.compedu.2014.06.004

Lajoie, S. P., Lee, L., Poitras, E., Bassiri, M., Kazemitabar, M., Cruz-Panesso, I., ... Lu, J. (2015). The role of regulation in medical student learning in small groups: Regulating 
oneself and others' learning and emotions. Computers in Human Behavior, 52, 601-616. doi:10.1016/j.chb.2014.11.073

Lakoff, G. (1972). Hedges: A study of meaning criteria and the logic of fuzzy concepts. In P. Peranteau, J. Levi, \& G. Phares (Eds.), Papers from the eighth regional meeting (pp. 183-228). Chicago, IL: Chicago Linguistics Society.

Lee, A., O’Donnell, A. M., \& Rogat, T. K. (2014). Exploration of the cognitive regulatory sub-processes employed by groups characterized by socially shared and other-regulation in a CSCL context. Computers in Human Behavior, 52, 617-627. doi:10.1016/j.chb.2014.11.072

Linnenbrink-Garcia, L., Rogat, T. K., \& Koskey, K. L. K. (2011). Affect and engagement during small group instruction. Contemporary Educational Psychology, 36, 13-24. doi:10.1016/j.cedpsych.2010.09.001

Miller, M., \& Hadwin, A. F. (2015). Scripting and awareness tools for regulating collaborative learning: Changing the landscape of support in CSCL. Computers in Human Behavior, 52, 573-588. doi:10.1016/j.chb.2015.01.050

Miyake, N., \& Kirschner, P. A. (2014). The social and interactive dimensions of collaborative learning. In K. R. Sawyer (Ed.), The Cambridge handbook of the learning sciences (pp. 418-438). New York, NY: Cambridge University Press.

Molenaar, I., \& Chiu, M. M. (2014). Dissecting sequences of regulation and cognition: statistical discourse analysis of primary school children's collaborative learning. Metacognition and Learning, 9, 137-160. doi:10.1007/s11409-013-9105-8

Mullins, D., Deiglmayr, A., \& Spada, H. (2013). Motivation and emotion shaping knowledge co-construction. In M. J. Baker, J. Andriessen, \& S. Järvelä (Eds.), Affective Learning Together: Social and emotional dimensions of collaborative learning (pp. 139-161). Abingdon, UK: Routledge. 
Määttä, E., Järvenoja, H., \& Järvelä, S. (2012). Triggers of students' efficacious interaction in collaborative learning situations. Small Group Research, 43, 497-522. doi:10.1177/1046496412437208

Mäkitalo-Siegl, K. (2008). From multiple perspectives to shared understanding: A small group in an online learning environment. Scandinavian Journal of Educational Research, 52, 77-95. doi:10.1080/00313830701786677

Näykki, P., Isohätälä, J., Järvelä, S., Pöysä-Tarhonen, J., \& Häkkinen, P. (2017). Facilitating socio-cognitive and socio-emotional monitoring in collaborative learning with a regulation macro script: An exploratory study. International Journal of ComputerSupported Collaborative Learning, 12, 251-279. doi:10.1007/s11412-017-9259-5

Näykki, P., Järvelä, S., Kirschner, P. A., \& Järvenoja, H. (2014). Socio-emotional conflict in collaborative learning: A process-oriented case study in a higher education context. International Journal of Educational Research, 68, 1-14. doi:10.1016/j.ijer.2014.07.001

Näykki, P., Järvenoja, H., Järvelä, S., \& Kirschner, P. (2017). Monitoring makes a difference: Quality and temporal variation in teacher education students' collaborative learning. Scandinavian Journal of Educational Research, 61, 31-46. doi:10.1080/00313831.2015.1066440

Pekrun, R., \& Linnenbrink-Garcia, L. (2012). Academic emotions and student engagement. In S. L. Christenson, A. L. Reschly, \& C. Wylie (Eds.), Hanbook of research on student engagement (pp. 259-282). New York, NY: Springer.

Pintrich, P. R. (2000). The role of goal orientation in self-regulated learning. In M. Boekaerts, P. R. Pintrich, \& M. Zeidner (Eds.), Handbook of self-regulation (pp. 451-502). San Diego, CA: Academic Press. 
Polo, C., Lund, K., Plantin, C., \& Niccolai, G. P. (2016). Group emotions: The social and cognitive functions of emotions in argumentation. International Journal of ComputerSupported Collaborative Learning, 11, 123-156. doi:10.1007/s11412-016-9232-8

Raes, E., Kyndt, E., Decuyper, S., Van den Bossche, P., \& Dochy, F. (2015). An exploratory study of group development and team learning. Human Resource Development Quarterly, 26, 5-30. doi:10.1002/hrdq

Remedios, L. J., Clarke, D., \& Hawthorne, L. (2008). The silent participant in small group collaborative learning contexts. Active Learning in Higher Education, 9, 201-216. doi:10.1177/1469787408095846

Rogat, T. K., \& Linnenbrink-Garcia, L. (2011). Socially shared regulation in collaborative groups: An analysis of the interplay between quality of social regulation and group processes. Cognition and Instruction, 29, 375-415. doi:10.1080/07370008.2011.607930

Roschelle, J. (1992). Learning by collaborating: Convergent conceptual change. Journal of the Learning Sciences, 2, 235-276. doi:10.1207/s15327809j1s0203_1

Roschelle, J., \& Teasley, S. D. (1995). The construction of shared knowledge in collaborative problem solving. In C. O’Malley (Ed.), Computer-supported collaborative learning (pp. 69-97). Berlin, Germany: Springer.

Sacks, H., Schegloff, E. A., \& Jefferson, G. (1974). A simplest systematics for the organization of turn-taking for conversation. Language, 50, 696-735. doi: $10.2307 / 412243$

Salomon, G., \& Globerson, T. (1989). When teams do not function the way they ought to. International Journal of Educational Research, 13, 89-99. doi:10.1016/08830355(89)90018-9 
Sargent, L. D., \& Sue-Chan, C. (2001). Does diversity affect group efficacy? The intervening role of cohesion and task interdependence. Small Group Research, 32, 426-450. doi:/10.1177/104649640103200403

Sinha, S., Rogat, T. K., Adams-Wiggins, K. R., \& Hmelo-Silver, C. E. (2015). Collaborative group engagement in a computer-supported inquiry learning environment. International Journal of Computer-Supported Collaborative Learning, 10, 273-307. doi:10.1007/s11412-015-9218-y

Sullivan, F. R., \& Wilson, N. C. (2015). Playful talk: Negotiating opportunities to learn in collaborative groups. Journal of the Learning Sciences, 24, 5-52. doi:10.1080/10508406.2013.839945

Wang, Q. (2009). Design and evaluation of a collaborative learning environment. Computers \& Education, 53, 1138-1146. doi:10.1016/j.compedu.2009.05.023

Weinberger, A., \& Fischer, F. (2006). A framework to analyze argumentative knowledge construction in computer-supported collaborative learning. Computers \& Education, 46, 71-95. doi:10.1016/j.compedu.2005.04.003

Winne, P. H., \& Hadwin, A. F. (1998). Studying as self-regulated learning. In D. Hacker, J. Graesser, \& A. Dunlosky (Eds.), Metacognition in educational theory and practice (pp. 277-304). Mahwah, NJ: Lawrence Erlbaum.

Volet, S. E., Summers, M., \& Thurman, J. (2009). High-level co-regulation in collaborative learning: How does it emerge and how is it sustained? Learning and Instruction, 19, 128-143. doi:10.1016/j.learninstruc.2008.03.001

Volet, S. E., Vauras, M., \& Salonen, P. (2009). Self- and social regulation in learning contexts: An integrative perspective. Educational Psychologist, 44, 215-226. doi:10.1080/00461520903213584 
Wolters, C. A. (2003). Regulation of motivation: Evaluating an underemphasized aspect of self- regulation of motivation. Educational Psychologist, 38, 189-205. doi:10.1207/S15326985EP3804

Zimmerman, B. J. (2000). Attaining self-regulation: A social cognitive perspective. In M. Boekaerts, P. R. Pintrich, \& M. Zeidner (Eds.), Handbook of self-regulation (pp. 13-39). San Diego, CA: Academic Press. 
Table 1. Joint participation and positive socio-emotional interaction during episodes with and without regulation in social interaction.

\begin{tabular}{lcccccc}
\hline & \multicolumn{2}{c}{$\begin{array}{c}\text { In episodes with regulation } \\
\left(M_{\text {dur }}=0: 33: 53\right)\end{array}$} & \multicolumn{2}{c}{$\begin{array}{c}\text { In episodes without regulation } \\
\left(M_{\text {dur }}=0: 25: 21\right)\end{array}$} \\
\cline { 2 - 7 } & $M_{\text {dur }}$ & $M \%$ & $S D \%$ & $M_{\text {dur }}$ & $M \%$ & $S D \%$ \\
\hline Joint focus & $0: 27: 54$ & $81 \%$ & $15 \%$ & $0: 16: 58$ & $68 \%$ & $19 \%$ \\
Joint contributing & $0: 15: 18$ & $46 \%$ & $15 \%$ & $0: 07: 49$ & $29 \%$ & $15 \%$ \\
Joint listening & $0: 19: 22$ & $58 \%$ & $14 \%$ & $0: 13: 48$ & $53 \%$ & $18 \%$ \\
Humor & $0: 10: 36$ & $30 \%$ & $11 \%$ & $0: 06: 41$ & $30 \%$ & $14 \%$ \\
Socio-emotional support & $0: 04: 43$ & $14 \%$ & $6 \%$ & $0: 01: 30$ & $6 \%$ & $5 \%$ \\
\hline
\end{tabular}

Note. The values are based on the analysis of 20 videos of collaborative group work. 
Table 2. Example of establishing agreement at 56:30-57:00 and 58:00-58:30.

\begin{tabular}{|c|c|c|c|c|c|c|}
\hline Time & Regulation & $\begin{array}{l}\text { Joint } \\
\text { participation }\end{array}$ & $\begin{array}{l}\text { Positive } \\
\text { socio- } \\
\text { emotional } \\
\text { interaction }\end{array}$ & Turn & Speaker & Transcript \\
\hline 56:00-56:30 & Planning & $\begin{array}{l}\text { Joint task } \\
\text { focus }\end{array}$ & & & & \\
\hline \multirow{10}{*}{$56: 30-57: 00$} & \multirow{10}{*}{ Monitoring } & \multirow{10}{*}{$\begin{array}{l}\text { Joint task } \\
\text { focus } \\
\text { Joint } \\
\text { contributing }\end{array}$} & \multirow{10}{*}{$\begin{array}{l}\text { Socio- } \\
\text { emotional } \\
\text { support }\end{array}$} & 1 & Maria & $\begin{array}{l}\text { Well, what topic would it be, then? Like what, how to motivate; } \\
\text { what would be such an interesting task? }\end{array}$ \\
\hline & & & & 2 & Ellen & $\begin{array}{l}\text { Well, do we, in any case, have the basic idea to produce? They } \\
\text { will produce their own maps? }\end{array}$ \\
\hline & & & & 3 & Maria & $\begin{array}{l}\text { Hh, nn... Well, I think it's one option ((opens her hands and holds } \\
\text { them out to the side)) but it is... }\end{array}$ \\
\hline & & & & 4 & Ellen & I think it is a good idea. ((turns her gaze to Maria)) \\
\hline & & & & 5 & Maria & Yeah. \\
\hline & & & & 6 & Ellen & Mm. ((gazes at Maria) $)$ \\
\hline & & & & 7 & Ellen & $\begin{array}{l}\text { I don't have the energy to start weighing options. ((continues } \\
\text { making notes)) }\end{array}$ \\
\hline & & & & 8 & Maria & $\begin{array}{l}\text { And then there doesn't like.... Then they could use the symbols } \\
\text { they know. }\end{array}$ \\
\hline & & & & 9 & Aaron & $\begin{array}{l}\text { It doesn't necessarily need to be a satellite. It's enough that it is } \\
\text { like an aerial picture taken from high enough ((gazes at tablet that } \\
\text { he is using for finding images)) }\end{array}$ \\
\hline & & & & 10 & Maria & $\begin{array}{l}\text { Yeah that is, that is really...! ((gazes at Aaron and nods as a sign } \\
\text { of approval)) }\end{array}$ \\
\hline $57: 00-57: 30$ & & $\begin{array}{l}\text { Joint task } \\
\text { focus }\end{array}$ & & & & \\
\hline 57:30-58:00 & Monitoring & $\begin{array}{l}\text { Joint task } \\
\text { focus }\end{array}$ & & & & \\
\hline 58:00-58:30 & Planning & $\begin{array}{l}\text { Joint task } \\
\text { focus }\end{array}$ & $\begin{array}{l}\text { Socio- } \\
\text { emotional } \\
\text { support }\end{array}$ & 11 & Maria & $\begin{array}{l}\text { But like how... Is it, like, meaningful enough? What... And would } \\
\text { there be, like, that they could kind of add something on their own, } \\
\text { so that they could kind of be designers also somehow that...? }\end{array}$ \\
\hline
\end{tabular}




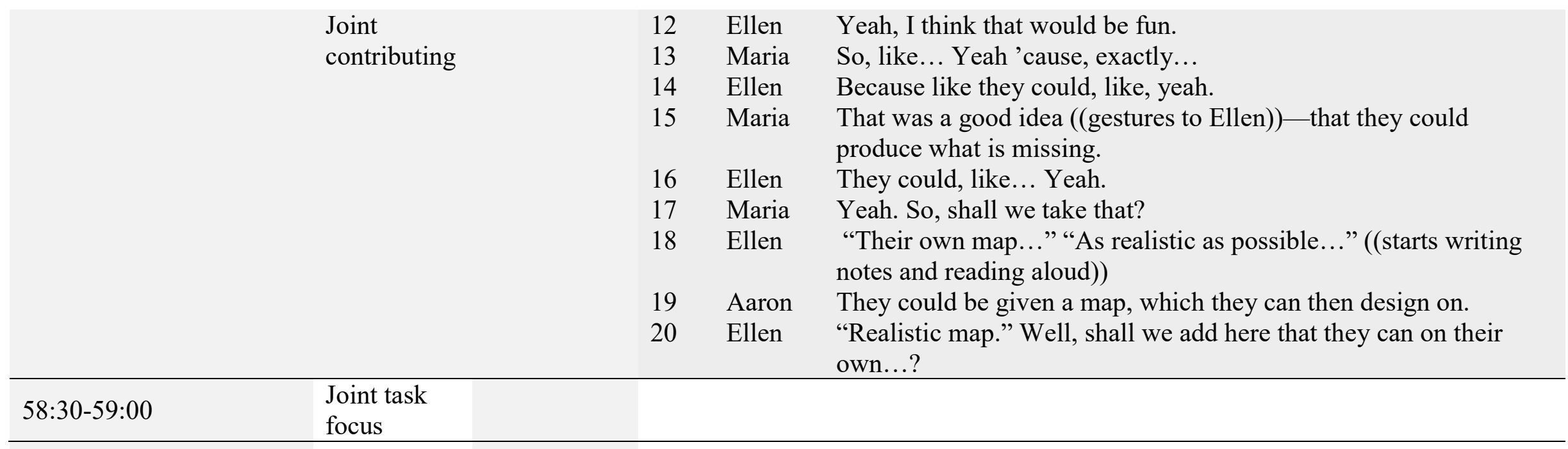


Table 3. Example of responding to challenges or mistakes at 44:00-45:30.

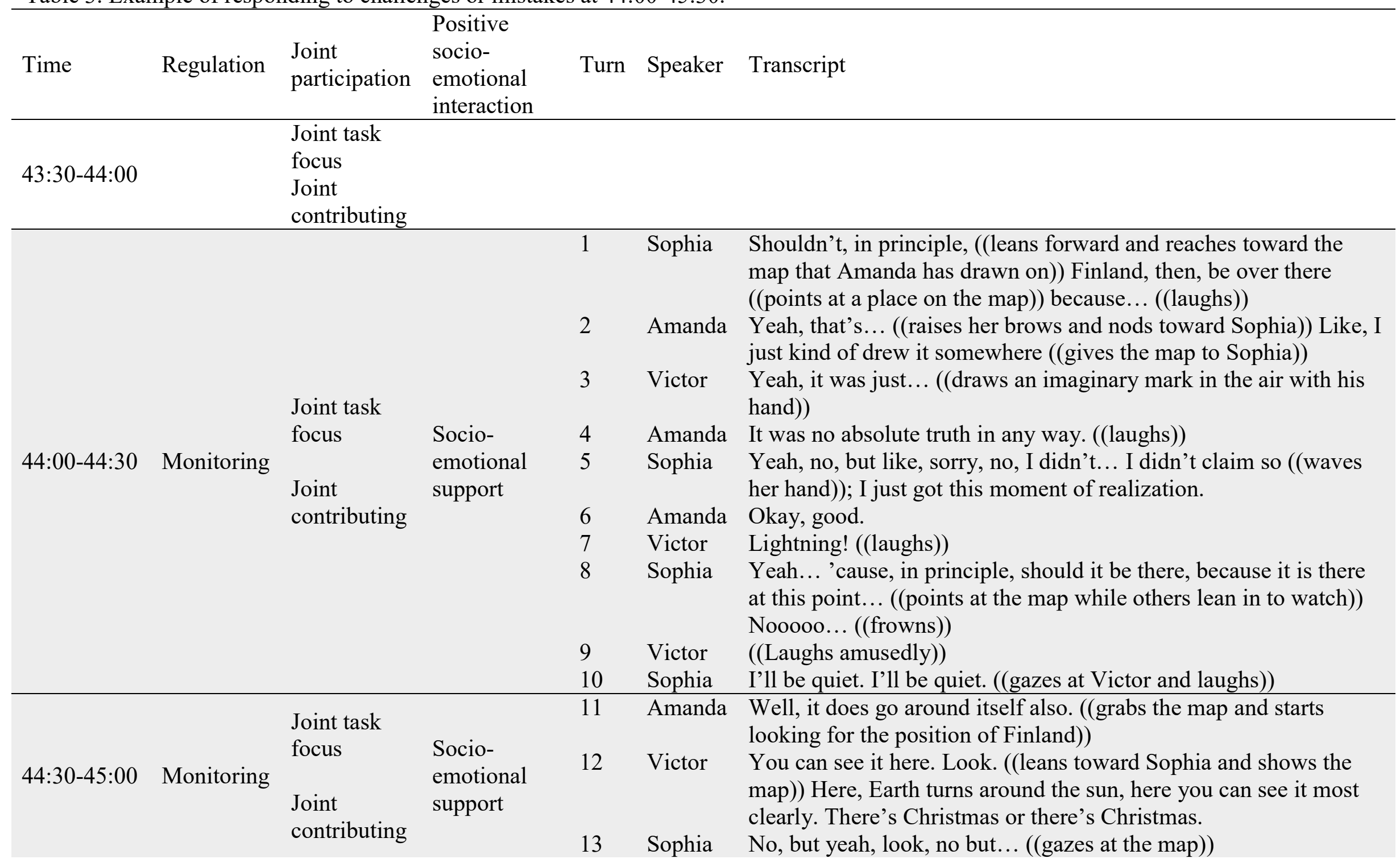




\begin{tabular}{|c|c|c|c|c|c|c|}
\hline & & & & $\begin{array}{l}14 \\
15 \\
16 \\
17\end{array}$ & $\begin{array}{l}\text { Victor } \\
\text { Sophia } \\
\text { Victor } \\
\text { Sophia }\end{array}$ & $\begin{array}{l}\text { Look, there's the U.S. } \\
\text { Ah, yeah. } \\
\text { America. } \\
\text { You had drawn it correctly, Amanda. I didn't have a moment of } \\
\text { realization after all. }\end{array}$ \\
\hline $45: 00-45: 30$ & Monitoring & $\begin{array}{l}\text { Joint task } \\
\text { focus } \\
\text { Joint } \\
\text { contributing }\end{array}$ & $\begin{array}{l}\text { Socio- } \\
\text { emotional } \\
\text { support }\end{array}$ & $\begin{array}{l}18 \\
19 \\
20 \\
21 \\
22 \\
23 \\
24 \\
25 \\
26 \\
27 \\
28 \\
29 \\
30\end{array}$ & $\begin{array}{l}\text { Amanda } \\
\text { Victor } \\
\text { Sophia } \\
\text { Victor } \\
\text { Amanda } \\
\text { Sophia } \\
\text { Amanda } \\
\text { Sophia } \\
\text { Amanda } \\
\text { Victor } \\
\text { Amanda } \\
\text { Sophia } \\
\text { Victor }\end{array}$ & $\begin{array}{l}\text { But, like, it does go around itself also, but the angle makes... } \\
\text { Yeah. } \\
\text { Yeah. } \\
\text { Right. } \\
\text { At what angle it is. } \\
\text { The angle is what I was thinking, but I won't show my stupidity } \\
\text { any further, so you won't laugh at me. } \\
\text { We won't laugh at you. ((slowly and seriously gazes at Sophia)) } \\
\text { Sometimes it's good to be quiet. ((smiles and gazes at Amanda)) } \\
\text { Yeah, true. ((laughs)) } \\
\text { Unless you tell a joke. } \\
\text { Then we can laugh. } \\
\text { That would be the joke of all jokes. ((laughs)) } \\
\text { ((laughs)) }\end{array}$ \\
\hline $45: 30-46: 00$ & & $\begin{array}{l}\text { Joint } \\
\text { contributing }\end{array}$ & $\begin{array}{l}\text { Socio- } \\
\text { emotional } \\
\text { support }\end{array}$ & & & \\
\hline
\end{tabular}


Table 4. Example of discussing strengths and weaknesses at 23:00-24:00.

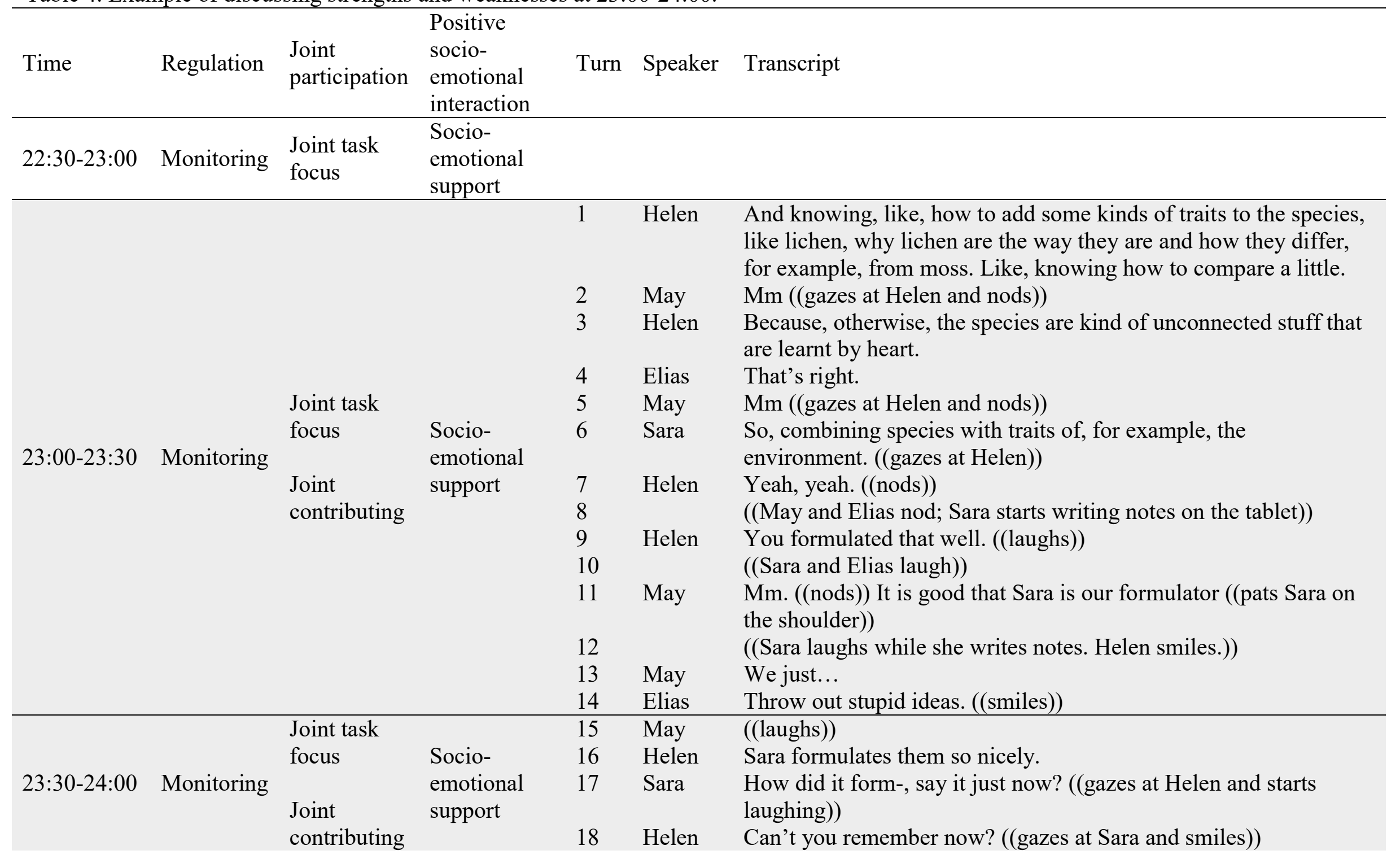




\begin{tabular}{|c|c|c|c|c|}
\hline & & $\begin{array}{l}19 \\
20 \\
21 \\
22 \\
23 \\
24 \\
25 \\
26\end{array}$ & $\begin{array}{l}\text { Sara } \\
\text { Sara } \\
\text { Elias } \\
\text { May } \\
\text { Sara } \\
\text { Helen } \\
\text { Sara }\end{array}$ & $\begin{array}{l}\text { No, ((laughing)) you mixed my thought up. } \\
((\text { Elias laughs and May smiles)) } \\
\text { "Species with traits of"... how did I say it? } \\
\text { I kind of missed it. } \\
((\text { laughs })) \\
\text { Are you saying you didn’t listen? ((laughs)) } \\
\text { Combining! Combining. } \\
\text { Yeah! ((lifts her index finger)) "Species with..." ((writes)) }\end{array}$ \\
\hline 24:00-24:30 & $\begin{array}{l}\text { Joint task } \\
\text { focus }\end{array}$ & & & \\
\hline
\end{tabular}


Authors' bios:

Jaana Isohätälä is a junior researcher at the Learning and Educational Technology research unit, University of Oulu, Finland. Her research focuses on the interplay of cognitive and socio-emotional processes in social interaction during collaborative learning. Her methodological expertise is on the process-oriented, qualitative analysis of video-recorded social interaction.

Piia Näykki is a post-doctoral researcher at the Learning and Educational Technology research unit, University of Oulu, Finland. She is working on her Academy of Finland funded project, studying emotion regulation in collaborative learning. She is experienced in processoriented and design-based research.

Sanna Järvelä is a professor and the head of the Learning and Educational Technology research unit, University of Oulu, Finland. Her scholarly contributions include theoretical work on social aspects self-regulated learning and the methodological development of process-oriented research methods in learning and collaboration. 